\title{
An Assessment of the Need for Follow-up of Patients with Pulmonary Tuberculosis Adequately Treated by Chemotherapy
}

\author{
BRITISH THORACIC AND TUBERCULOSIS ASSOCIATION JOINT TUBERCULOSIS COMMITTEE \\ REPORT*
}

Until recently the treatment of tuberculosis was so unsatisfactory that patients who survived were kept under indefinite supervision because relapse was frequent. As well as clinical, radiological, and bacteriological examination this entailed advice over much of the patient's life-work, recreation, child-bearing, and so on. Now such is the efficacy of antituberculous treatment that the time is ripe for a revaluation of the need for supervision. Evidence will be presented to show that with certain important exceptions, and, with safeguards, patients believed to have taken prescribed adequate chemotherapy (see below) need not be kept under supervision.

The exceptions will be mentioned first. They are patients with "high risk factors."

\section{High Risk Factors}

Poor co-operation leading to inadequate treatment is the most important factor in relapse. Every effort must therefore be made to identify uncooperative patients early.

There is a hard core of persons with psychopathic traits who will never co-operate (unless in a prison hospital), and some with other psychiatric disorders fail to do so, but there are others who need constant encouragement to retain their co-operation. A good doctor-patient relationship is most important, and the health visitor too has a valuable role. Spot tests on urine are most important. The patient must be made to understand that he will become well and remain well only if he takes the prescribed treatment. Unfortunately patients who fail to take the treatment are apt not to attend for follow-up.

Co-operation may be easier to achieve now that PAS is being replaced by more acceptable drugs, for its side effects may frequently have deterred patients from continuing with treatment.

Alcoholism figures high in American reports but less often in

- The report was prepared by a subcommittee of the Joint Tuberculosis Committee consisting of Dr. T. A. Watkin Edwards (Convenor), Dr. R. B. Illing, Dr. J. R. Lauckner, and Dr. K. M. Citron; and approved by the Joint Tuberculosis Committee, whose members at the time were Dr. T. A. Watkin Edwards, Dr. R. H. Townshend, Dr. F. Ridehalgh, Dr. Audrey Hanson, Professor J. W. Crofton, Dr. J. R. Bignall, Dr. J. D. Ball, Dr. J. R. Mikhail, Dr. W. H. Tattersall, Dr. J. Wallace Fox, Dr. K. M. Citron Mr. P. P. Brown, Dr. D. K. Stevenson, Dr. N. V. Williams, Dr. N. Lloyd Dr. P. P. Brown, Dr. D. K. Stevenson, Dr. N. V. Williams, Dr. N. Lloyd Rusby, Dr. R. Grenville-Mathers, Mr. R. H. F. Brain, Mr. M. H. Carr, Dr. F. J. W. Miller, Dr. D. H. Smith, Dr. G. Anderson, Dr. S. A. C. Eunter, Dr. R. G. May, Dr. J. R. Lauckner, Dr. C. A. Hopkins, Dr. G. F. Edwards, Dr. D. R. Lewis,
Hughes, Dr. D. M. Gregg.
British. In general, a higher than average risk of relapse is associated with diabetes, treatment with corticosteroids, partial gastrectomy, and chronic debilitating disease. Patients with these disabilities should remain under permanent supervision. Patients with large residual "open healed cavities" should be kept under observation because of the risk of the development of mycetoma; they may, if suitable, be considered for resection.

\section{Adequate Chemotherapy}

There are only two groups of treated tuberculous patients: (a) those who have been prescribed and have taken appropriate orthodox standard chemotherapy for 18 to 24 months; (b) those who have not been so treated. The latter group will include patients treated before effective chemotherapy was available, and patients treated in the early days of chemotherapy when short courses of chemotherapy were regarded as preparation for some form of collapse therapy. In addition there is a small number of non-cooperative patients, some known, others suspected but not proved. This paper is concerned with group $(a)$.

Adequate chemotherapy must be defined. Orthodox standard chemotherapy means streptomycin, PAS, and isoniazid, the streptomycin being given for varying periods and PAS and isoniazid for 18 to 24 months. The definition also implies that the patient has taken the treatment as prescribed. With the introduction of ethambutol and rifampicin and the possibility, now being investigated, that shorter courses of these drugs may be adequate the definition of orthodox standard chemotherapy may change. Patients treated with these drugs should at present be followed up to gain information about the relapse rate.

Sensitivity tests will usually indicate whether the prescribed treatment is appropriate, but a minority of patients never produce a positive sputum and therefore cannot have sensitivity tests done. There is a slight risk here that incorrect chemotherapy might be prescribed. This is unlikely if the newer drugs are given, and radiological progress would probably indicate whether the lesion was responding to treatment.

\section{Frequency of Relapse}

The overall relapse rate is low, 0 to $4 \% .{ }^{12}$ These figures relate to all treated patients and include some subject to high-risk factors. If these patients are excluded the relapse rate is extremely low.

Until recently few long-term follow-up results were available. Stead and Jurgens ${ }^{3}$ found only three relapses in 372 patients who had remained well for three years after receiving chemotherapy for 18 months or more and followed up for three to nine years, and no relapses in 187 patients followed up for 10 to 14 years. 
Edsall and Collins ${ }^{4}$ reported that of 13000 patients in New York City attending for routine follow-up in 1970 approximately 200 to 250 patients were considered to have reactivation of disease. Approximately 80 of these were identified by routine follow-up, the remainder by development of symptoms. All but three of these 80 had other problems for which medical supervision was indicated, though not necessarily in a chest clinic.

Bailey et al. ${ }^{5}$ found that in New Orleans in 1965-72 63 (4\%) of 1585 patients added to the register with active pulmonary tuberculosis had reactivated disease. Of these, six had had no previous chemotherapy, three had had streptomycin only, 47 had had combined chemotherapy self-interrupted or selfdiscontinued, and only seven had had two years' combined chemotherapy. Adverse influences were present in 41 of the 47 non-cooperative patients-mental illness in six, drug addiction in two, "petty criminality" in two, alcoholism in 31. Of the relapses $60 \%$ were detected by the development of symptoms. Pearce and Horne reported $^{6}$ on 825 patients treated during 1955-60 and followed up for periods up to 18 years. Most received "triple chemotherapy with PAS, isoniazid and streptomycin." Thirty-three patients $(4 \%)$ relapsed, with positive sputum cultures, and in 30 of these cases the relapse was attributable to inadequate treatment as a result of poor co-operation; $58 \%$ of relapses were detected at routine follow-up clinics. The relapse rate was lowest in the age group 0 to 24 years $(1 \cdot 1 \%)$ and highest in the age group 45 to 64 years $(7 \cdot 2 \%)$. The relapse rate in men was $4.9 \%$ and in women $2.5 \%$. In these two series the relapse rate among patients who had taken appropriate chemotherapy was very low. In the series reported by Bailey et $a l .{ }^{5}$ the relapse rate was only 7 out of $1585(0.43 \%)$ and in Pearce and Hornes series ${ }^{6}$ it was 3 out of $825(0.36 \%)$. Of the three co-operative patients who relapsed one had been taking $10 \mathrm{mg}$ of prednisolone for asthma for four years; another relapsed with resistant organisms, probably the result of the method used to desensitize her to the drugs given.

\section{Time of Relapse}

Reports show that relapse usually occurs within five years of the start of treatment. In Pearce and Horne's series ${ }^{6}$ only eight of 33 relapses were detected more than five years from the start of treatment.

\section{Attitude of Patient to Prolonged Follow-up}

A leading article in Tubercle? suggested that "long continued supervision could still be psychologically harmful for the patients. Many, after one and a half to two years of attending clinics, would be delighted to be told that they were no longer patients and need not attend again; that they were healthy people who need not be observed or their lives supervised." This may not always be true. Patients accustomed to a yearly check do not always welcome the suggestion that they need not attend again. They feel relieved and happy if they are told all is well. However, patients now being treated and not conditioned to follow-up might well be glad to know they need not come again.

\section{Conclusion}

A third to a half of all relapses are detected by other means than routine follow-up. Except for patients with high-risk factors the follow-up of patients believed to have taken standard chemotherapy as defined for 18 to 24 months is no longer justified. But the discharged patient must be encouraged to return to the clinic if he develops symptoms that might indicate a relapse. It is therefore most important to keep the patient's general practitioner fully informed and for him to refer treated tuberculous patients back to the clinic if he has any reason to suspect relapse or if the patient develops any of the conditions referred to under "high risk factors."

\section{References}

1 Thomas, H. E., Bulletin of the International Union against Tuberculosis (Excerpta Medica I.C.S. no. 205), 1970, 43 (June), 239.

2 Springett, V. H., Tubercle, 1971, 52, 73

Stead, W. W., and Jurgens, G. H., American Review of Respiratory Disease, $1973,108,314$

4 Edsall, J., and Collins, G., American Review of Respiratory Disease, 1973, 107,851 .

5 Bailey, W. C., et al., American Review of Respiratory Disease, 1973, 107, 854 .

6 Pearce, S. J., and Horne, N. W., Lancet, 1974, 2, 641.

7 Tubercle, 1973, 54, 247

\title{
Conversations with Consultants
}

\section{Professional Satisfaction is Still Just Alive}

\author{
FROM A SPECIAL CORRESPONDENT
}

British Medical fournal, 1975, 2, 29-30

\begin{abstract}
"My patients have rarely mentioned the dispute," commented the plastic surgery consultant. "One father was a bit stroppy-I thought because of his son's delayed operation. But it turned out his complaint was that doctors hadn't acted militantly so as to end the dispute quickly." "Some of my patients," said another surgeon, "were most surprised to hear that I didn't get paid extra for night work." The patients of yet another seemed ignorant of the consultant's row with the Government.

So it seemed unlikely, judged by this group of consultants drawn from a large English city, that public opinion was as yet a significant influence either way on the consultants' dispute. Indeed, they were emphatic that the extra holidays for nurses
\end{abstract}

(proposed by Lord Halsbury*) had closed more beds and lengthened waiting lists more effectively than their own workto-contract. Empty beds there certainly were, and the consultants in the area had reduced their work load, with one wife observing how nice it was to see more of her husband in the evenings. Nevertheless, theirs seemed a gentlemanly response to recent events in the N.H.S.

\section{No Illusions}

They had no illusions, however, about the future. The air of resigned anger with which they criticized the N.H.S. was more devastating than any militant polemics. Four years previously,

*B.M.F. 28 September 1974, p. 762. 